\title{
Intervención de enfermería sobre dieta y actividad física en una unidad de hemodiálisis
}

\author{
Elena Ausejo San José, Natalia Pérez Mendióroz, Pilar Amezqueta Goñi, Nuria García Fernández
}

\section{Clínica Universidad de Navarra. Pamplona. Navarra}

\section{Introducción:}

Los pacientes con enfermedad renal crónica en tratamiento habitual de hemodiálisis requieren un seguimiento continuado de su estado físico en el que deben incluirse la dieta y ejercicio. La implicación activa e instauración de un protocolo por parte de enfermería resulta fundamental en este sentido. El protocolo a seguir se ha basado en la siguiente metodología: Entrevista. Parámetros bioquímicos. Parámetros antropométricos. Dinamometría. Bioimpedancia. Escalas de valoración nutricional. Los parámetros se tomaron en el tiempo según pauta predeterminada y se adelantaron cuando existía riesgo de desnutrición. Las medidas terapeúticas fueron: consejos dietéticos adecuados y ejercicio (pedaleo, caminar, bicicleta...).

\section{Objetivo:}

Valorar el impacto clínico de la implantación de un protocolo de enfermería con control de la alimentación y ejercicio en pacientes en hemodiálisis.

\section{Metodología}

Estudio observacional retrospectivo iniciado en junio de 2012 con la implantación del protocolo de enfermería. Se inició con 44 pacientes, 19 mujeres y 25 hombres. Las variables estudiadas al inicio y a los 6 meses fueron: Cuestionario de actividad física, fuerza muscular (dinamometría), índice de masa corporal -IMC-, prealbúmina y body cell mass index -BCMI- (bioimpedancia). Además se registraron el número de ingresos de los pacientes del estudio en los 6 meses previos a la instauración del protocolo y se compararon con los 6 meses posteriores. Los resultados fueron expresados como: media (desviación estándar) analizados con programa excel.

\section{Resultados:}

A los 6 meses concluyeron el estudio 39 pacientes, 19 mujeres y 20 hombres. Causas de abandono: (4) por trasplante y (1) por éxitus. La edad media fue de 60,9.

En la Tabla 1 se presentan los resultados de las variables cuantitativas sin observar diferencias significativas en ninguna de ellas, si bien partían de valores normales. En los 6 meses previos a la instauración del protocolo hubo 29 ingresos y en los 6 meses post-protocolo hubo 20 ingresos.

\begin{tabular}{|l|c|c|c|c|}
\hline & $\begin{array}{c}\text { Fuerza } \\
\text { muscular } \\
\mathbf{( K g )}\end{array}$ & $\begin{array}{c}\text { IMC } \\
\mathbf{( K g /} \\
\mathbf{m} 2)\end{array}$ & $\begin{array}{l}\text { Prealbúmi- } \\
\text { na }(\mathbf{m g} / \mathbf{d l})\end{array}$ & BCMI \\
\hline Basal & $\begin{array}{c}23,18 \\
(12,75)\end{array}$ & $\begin{array}{l}24,91 \\
(4,68)\end{array}$ & $30,18(9,1)$ & $\begin{array}{c}8,95 \\
(4,22)\end{array}$ \\
\hline A los 6 meses & $\begin{array}{c}23,57 \\
(12,81)\end{array}$ & $\begin{array}{l}24,82 \\
(4,75)\end{array}$ & $30,88(8,29)$ & $\begin{array}{c}8,82 \\
(3,6)\end{array}$ \\
\hline
\end{tabular}

Tabla 1. Datos expresados como: media (desviación estándar)

\section{Conclusiones:}

No se objetivan cambios significativos tras la intervención de enfermería en el periodo de tiempo del estudio realizado. No obstante, y aunque el periodo de observación de nuestro estudio es muy corto, es posible que este tipo de intervenciones enlentezca el deterioro propio de los pacientes 
en programa de hemodiálisis. Para demostrarlo, habría que comparar nuestro grupo de pacientes con otro grupo de pacientes no sometidos a este protocolo. Se ha observado una disminución en el número de ingresos tras la implantación del protocolo. Los resultados obtenidos podrían variar llegando a ser significativos si se alargara el tiempo del estudio y/o si se incluyeran distintas variables.

\section{Referencias Bibliográficas}

1. Pérez Martínez J, Llamas Fuentes F, Legido A: Insuficiencia Renal Crónica, revisión y tratamiento conservador. Archivos de medicina, Vol.1, nº 3, 2005.

2. Allen R. Nissenson, Richard N. Fine: Manual de diálisis. Cuarta edición: 687-701, 2009.
3. Martins M, Marqués-Lopes I, Purroy A, Solozabal C, Sorbet MJ, Martínez JA: Efectos de una intervención dietética sobre el estado nutricional de pacientes en hemodiálisis: diferencias entre varones y mujeres. Revista Anales, 2010.

4. Lorenzo Sellarés V, López Gómez JM, Francisco Hernández ALM, Hernández Marrero A: Nefrología al día. Sociedad Española de Nefrología. 459471, 2010.

5. Cabañas Armesilla Dolores: Antropometría e Índices de Salud, 2008.

6. Riella Martins: Nutrición y Riñón. Protocolo de procedimientos nutricionales: 333-368, 2003.

7. Huarte-Loza E, ET AL: Nutrición en pacientes en diálisis. Consenso SEDYT. 